\title{
Tunga penetrans-A Silent Setback to Development in Kenya
}

\author{
Simon Kiprono Ruttoh ${ }^{1}$, Denis Ochieng' Omondi ${ }^{2}$ and Nafula Inviolata Wanyama ${ }^{3}$ \\ 1. School of Public Health, College of Health Sciences, Moi University, Eldoret 4606 30100, Kenya. \\ 2. C/o Joanes Omondi, Kisumu Municipal Council, Kisumu 105 40100, Kenya \\ 3. Bungoma 1915 502000, Kenya
}

Received: September 29, 2010 / Accepted: April 1, 2011 / Published: April 20, 2012.

\begin{abstract}
Tungiasis is an ectoparasitic skin disease caused by the penetration of the female sand flea, Tungapenetrans, into the epidermis of the host. Through an intensive literature review, poor hygiene, poverty, social neglect, ignorance, and poor cultural beliefs were found to promote jigger infestation in Kenya. The research revealed the vicious cycle of poverty, low educational standards, low self-esteem/stigmatization, violation of civil rights, HIV/AIDS and secondary infections as the effects of the infestation. Fumigation, on-host treatment of animals, proper hygiene, and health education are the suggested control measures. Generally, one needs to be physically, emotionally and socially sound to appropriately deliver the much needed services of national development. The jigger infestation negatively impacts on these aspects of human health, hampering the wholesome participation in nation building by both the infected and the affected. As a country, the Jigger menace is frustrating Kenya's attempts to achieve the Millennium Development Goal on poverty reduction by the year 2015 , as well as reducing the pace of national development.
\end{abstract}

Key words: Tunga penetrans, jigger infestation, poverty, hygiene, fumigation, national development.

\section{Introduction}

Tungiasis is an ectoparasitic skin disease, caused by the penetration of the female sand flea, Tungapenetrans, into the epidermis of the host [1]. It is endemic in developing countries in the tropics, particularly where poverty and poor standards of basic hygiene exist, like in the resource poor communities of South America, the Caribbean and sub-Saharan Africa, where it is an important but neglected health problem [2].

Newly emerged adults are agile, jumpy and crawl on the ground until they locate a suitable host, usually man. Pigs, dogs, cats, cattle, sheep and Rattus rattus are important reservoirs. The dogs and cats act as important reservoirs for the intra- and peridomiciliary transmission of sand fleas [3-5].

Both sexes feed on blood but whereas the male soon

Corresponding author: Simon Kiprono Ruttoh, Ph.D., research field: jiggers infestation in Kenya. E-mail: simonruto@gmail.com. leaves the host after taking a blood meal, the fertilized female burrows by aid of its sharp and well developed mouthparts into the soft areas of the skin, such as the toe webs or under toenails [6]. The sole, elbows and knees of heavily infested people may also be infected [7].

The first evidence of infestation by this sand flea is a tiny black dot (lesion) on the skin at the point of penetration. The area around the embedded flea becomes very itchy and inflamed leading to ulcerations, lymphangitis, and accumulation of pus (sepsis). When the female fleas die, they remain embedded within the host, frequently causing inflammation and consequently secondary infections. If ignored it, it leaded to gangrene, auto-amputation of digits, loss of toes, tetanus, or even death [6, 7].

As societies seek to develop, they often tend to forget the key elements, which if addressed, could make the societies really match their goals. Through attainment of vision 2030, Kenya hopes to achieve 
more than 10 percent economic growth, thus it can eradicate poverty. This truism therefore cannot be more apt [7].

The natural history of clinical human tungiasis develops in five stages. Phase I starts with penetration of the adult flea into the epidermis, leading to a rigorous inflammation and dilation of blood vessels in the dermis. In phase II, the flea thrusts its head into the superficial layers of the dermis, feeding on blood vessels. The hind part of the flea remains on the skin surface, maintaining communication with the outside. This provides air for breathing and a passage for both excretions and eggs. During phase III, the parasite produces up to 200 white ovoid eggs, causing her body to swell up to $7 \mathrm{~mm}$. The insect can now be seen as a yellow-whitish lesion under a hard hyperkeratotic skin. Phase IV starts after deposition of the eggs. The female flea dies and the carcass is expelled. During phase V, reorganization of the epidermis occurs, taking approximately four weeks, leaving minor residues that will stay for months. Meanwhile, the eggs that were left during phase III hatch in three to four days, liberating larvae that develop into pupae. After two weeks, the pupae become adult fleas, completing the cycle $[1,5]$.

Treatment requires the mechanical removal of the flea with a sterile pin, followed by an antiseptic dressing. Kerosene application kills the flea but results into ulceration of the skin until the dead flea is expelled [8].

According to Ahadi Trust Foundation, jiggers have continued to create havoc in rural areas and many school going children have dropped out of school because they are unable to walk [7].

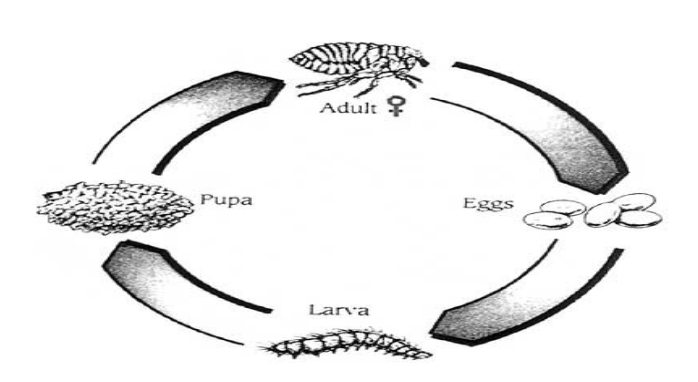

(a)

\section{Methodology}

An intensive literature review was done, both in electronic and non-electronic media. The search words used for the web search were Tunga penetrans in Kenya, Tunga penetrans infestation, effects and control of jiggers, Ahadi Kenya. Google search was the main search machine used, and the sites visited included Cochrane and Pubmed. The data was analyzed and compiled.

\section{Results and Discussions}

\subsection{Causes of Escalated Jigger Infestation}

\subsubsection{Poor Hygiene}

Infestation is brought about by lack of hygiene. During one of the visits by the Ahadi Kenya team to Murang'a District, it was established that most of the residents shared their houses with the domestic animals.

“... she confirms that she shares her sleeping quarters with chickens-perfect carriers of the fleas" [7].

When humans live in close contact with infested animals, the risk of infestation is high and the intensity of infestation is also high. These animals continue spreading $T$. penetrans and contribute to ongoing transmission in the community as long as they still get contact with the human beings $[5,9]$.

A study on Jiggers prevalence in Kituro Sub-location in Baringo Central District (August 2009) revealed that most of the respondents' compounds were not adequately clean, prompting the heavy jigger infestation in the area [10].

Fifty six percent and 79\% of respondents who

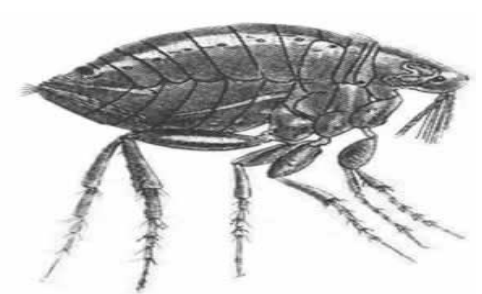

(b)

Fig. 1 (a) The life cycle of Tunga penetrans; (b) The adult Tunga penetrans. 
participated in the study in Baringo Central and Kisii Central Districts respectively had not observed adequate hygiene of their compounds. This had contributed to the high infestation rates in these areas. This is because dirty environment provides good breeding grounds for the jiggers. The same study revealed a low rate of floor smearing in Baringo Central, further contributing to the escalated infestation [10, 11]. Frequent smearing could have checked the spread, as it keeps the dust down, hence depriving the pest of adequate breeding grounds.

A similar study in Nyaura and Nyanchwa Sub locations of Kisii Central District (August 2009) reported the following states of houses, promoting the high prevalence of the pest in the area.

\subsubsection{Poverty}

Foot ware can hardly be afforded by poor people. Moreover, when the community is generally poor, most houses are made of mud walls and earthen floors. A study in Baringo Central District in Kenya showed $88 \%$ of the respondents having earthen and cracked walls on their houses, with dusty floors [10].

Poverty among the people impedes ownership of cemented houses, shoes and other vital sanitary effects. This compels them to walk bare footed, reside in poorly structured houses and share the houses with the domestic animals which are reservoirs of the pest. By this way, the pest perennially attacks them.

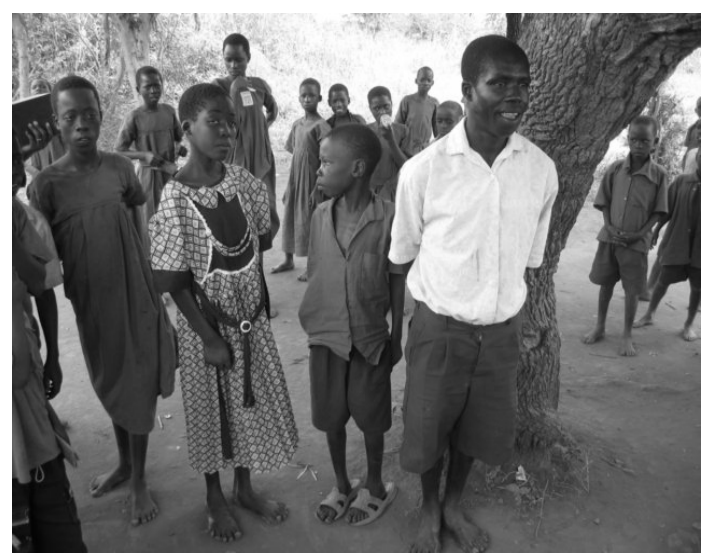

(a)
Classrooms, which often had an earth floor, were also points of infestation. This was according to Ahadi Kenya's report on the jigger situation in rural schools in Busia and Teso Districts [7].

Classrooms made of mud walls and earthen floors increase the attack in pupils as the floors are normally dusty. The situation is aggravated by the high pupil enrolment and the small size of the classrooms. This enormous number of pupils makes dust accumulate in the classroom very fast and make perfect breeding

\section{Cleanliness of homesteads}

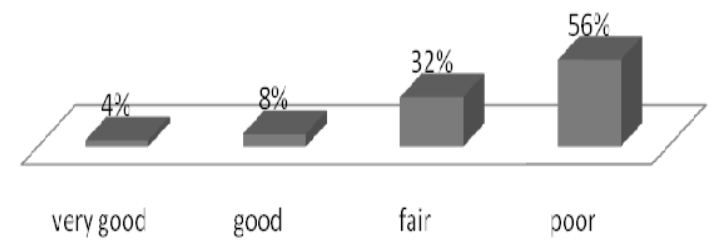

Fig. 2 Bar chart illustrating homestead cleanliness in Baringo Central District, 2009 (Alfred-unpublished data) [10].

\section{STATE OF HOUSING}

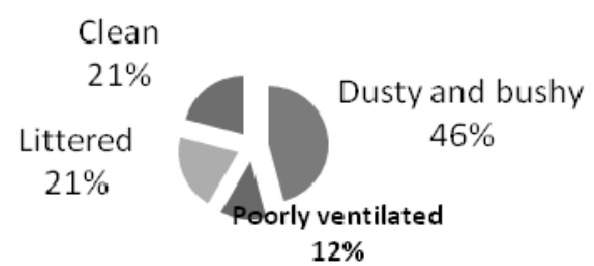

Fig. 3 Adapted from a report of Kisii Central District, 2009 [11].

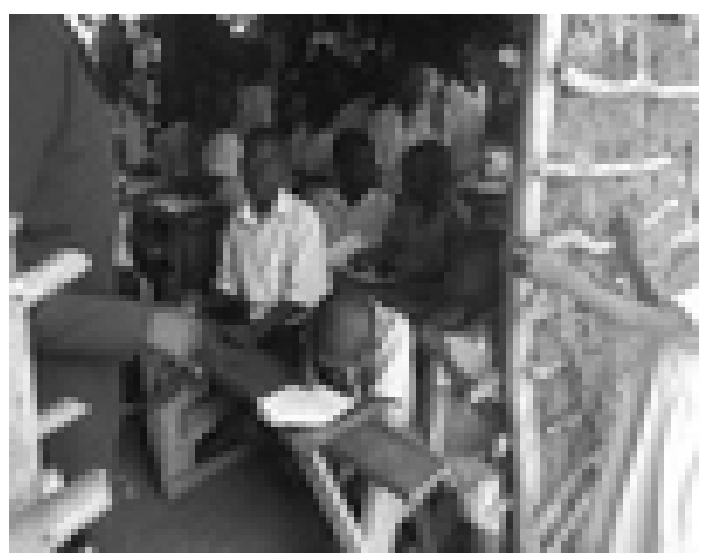

(b)

Fig. 4 (a) Bare footed school children; (b) Congested mud-walled classroom with earthen floor (adapted from Ahadi Kenya photos) [7]. 
ground for jiggers [7].

\subsubsection{Fear of Stigmatization}

During Ahadi Kenya's visit to Murang'a, it emerged that the jigger victims were stigmatized in the communities, making them shy away from seeking treatment as they did' $t$ want to be recognized as being infested. Below is a quotation from one of the female respondents during the Ahadi Kenya team's visit to Murang'a.

“... I would rather hide in my hut than seek treatment because then, my family will become the laughing stock of the village".

This was also noted in Baringo Central Distict where a research report showed that $88 \%$ of the respondents preferred home-based treatment to hospital care, as a result of fearing to let many people know about their condition.

\subsubsection{Prolonged Dry Spells in the Country}

A study conducted in Brazil revealed that the disease has a considerable seasonal variation, with the prevalence of tungiasis being highest at the peak of the dry season (September, 54.4\%) and lowest after the first rain of the rainy season (January, 16.8\%).

A similar trend is seen in Kenya, as reported by a number of respondents during the Ahadi Kenya team visit to Murang'a District.

“... we have had to succumb to jiggers-they are part of our family. The jiggers are seasonal and at their peak during the hot season," says one of the respondents.
From the graph on variation of the infestation with seasons, the prevalence is seen to increase with drier weather and reach its peak when precipitation is zero. It then decreases with the onset of rains at the end of the year. Conceivably, high humidity in the soil impairs the development of free-livingstages of $T$. penetrans. Furthermore, heavy rains may simply wash away the eggs, larvae, pupae, nymphs, and adult fleas [12].

Therefore, control measures aimed at reducing morbidity should be scheduled to be in place before the attack rate increases, i.e., at the beginning of the dry season and focusing on the most vulnerable population groups, namely children and the elderly, for effective control.

\subsection{Effects of Jigger Infestation}

\subsubsection{The Vicious Cycle of Poverty}

Ahadi team visit to Murang'a established that the jigger infestation contributed to the appalling poverty levels in the area. The following is a statement taken from one of the Ahadi Kenya reports:

“... both her hands and feet are infested. She can barely nurture her young ones as she is drained of energy. One look at her children reveals appalling malnutrition”.

The report revealed that the jigger infestation has made the residents to languish in the quagmire of the vicious cycle of poverty as illustrated in Figs. 1-6.

People afflicted with jiggers are less economically active, which raises poverty levels. Since jiggers are

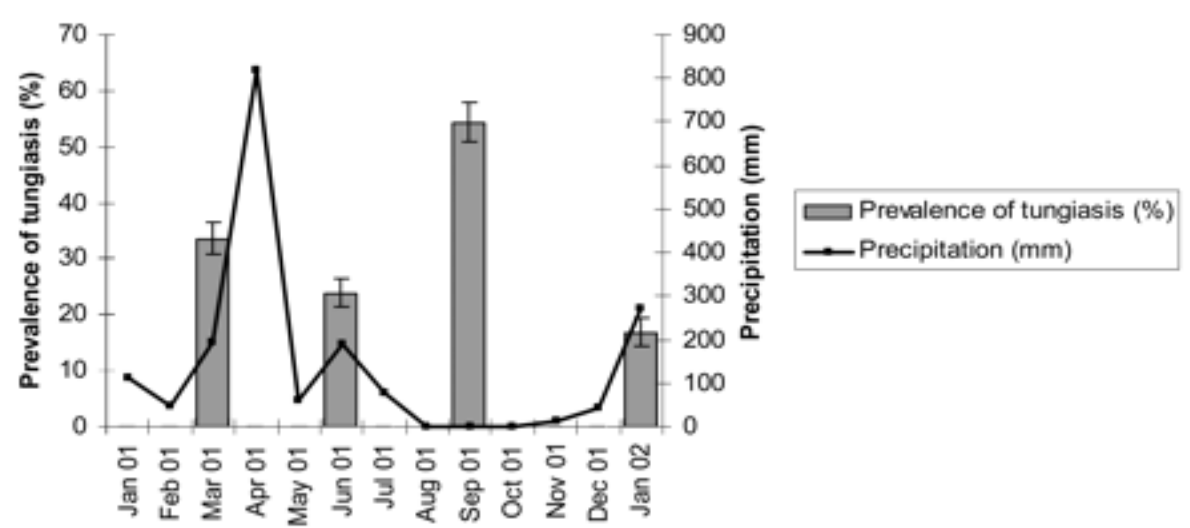

Fig. 5 Seasonal variation of the prevalence of tungiasis (bar graph) and monthly precipitation from January 2001 to January 2002 in Fortaleza, northeastern Brazil [12]. 


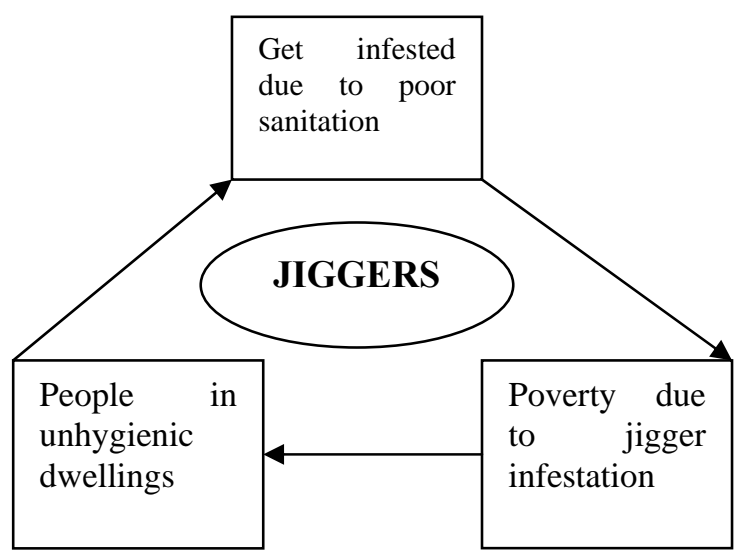

Fig. 6 Vicious poverty cycle due to jigger infestation.

usually a result of already existing poverty, their infestation perpetuates the vicious cycle of poverty where the poor are unable to rise out of poverty or actually often sink deeper into it. This frustrates Kenya's attempts to achieve the Millennium Development Goal, which aims at reducing levels of poverty in the country by a half by the year 2015 [7].

Jigger removal is a laborious process that consumes time needed for economic activity and the education of children. This further perpetuates poverty in the infested communities.

\subsubsection{Discomfort and Related Infections}

The presence of the jigger in the skin causes a severe itching sensation and general discomfort [6]. When the jigger is manually extracted, mall wounds are left around the feet and since the victims walk barefoot, walking becomes an agonizing exercise. Grass and small stones get into the holes left by the extracted fleas and cause excruciating pain [7].

Removal of jiggers with shared pins and other unsterilized removing equipments that may have been used by an HIV/AIDS victim may lead to the spread of HIV/AIDS and other communicable diseases. The wounds created by the infestation further act as entry points for microbial infection. Heavy infestations can lead to severe inflammation, ulceration (as shown in Fig. 7) and fibrosis. Tetanus, Lymphangitis, gangrene, sepsis may emerge as secondary infections [9]. This is because during penetration, the flea breaks up the stratum corneum, allowing bacterial micro colonies on the skin surface to spread.

In addition, pathogenic microorganisms on the outer surface of the flea may be actively carried into the epidermis. Moreover, when the flea dies in the flesh of the victim, the saprophytic bacteria thrive, which lead to secondary infection [5]. The loss of toenails, auto amputation of the digits and even death are potential outcomes [9].

\subsubsection{Low Education Standards}

According to Ahadi Kenya Trust, 800 school going children in Malindi, 5,000 in Kandara-Kiambu, 6,000 in Samburu and 400 in Narok District among other places had dropped out of school due to the infestation by November 2008.

Jigger infestation affects the education of children because they may be unable to walk to school, write properly, or participate in normal learning activities on the same level with other uninfested children. These, coupled with the intimidating ridicule from their peers, prompt repeated absenteeism from school and in some cases result into dropping out of school [7].

\subsubsection{Low Self Esteem Due to Stigmatization}

The parasite causes pain in affected parts and injury
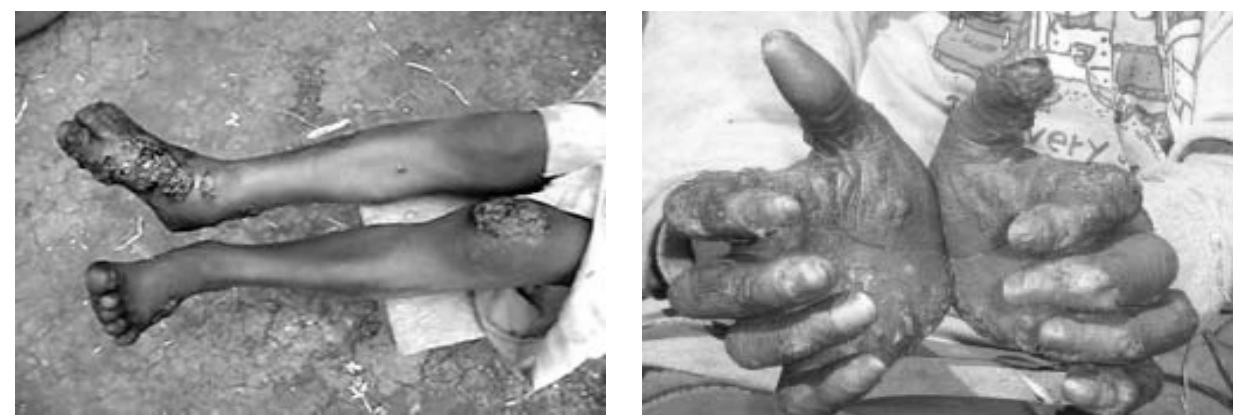

Fig. 7 Severely ulcerated feet and hands of children due to heavy jigger infestation (adapted from Ahadi Kenya Photos) [7]. 
that can seriously impede movement and performance of many of life's chores, making a person dependent on others who may themselves be unable to help due to their own affliction within the family. Jigger infestation and the process of their physical removal, as practiced in the villages, is a painful and traumatic experience, especially for children [7]. The ulcerations and auto-amputation of the digits make the victims feel ashamed of being in social places. It generally reduces their self esteem.

Stigmatization contributes to persistent jigger infestation. This is because victims prefer self medication (which in most cases is inappropriate) to hospital treatment, fearing to be ridiculed by their uninfested neighbors and even health workers [7]. This makes the life cycle of the pest to persist and continued spread of the flea is enhanced, as the eggs will continue being hatched and finding new hosts or re-infesting the same victim.

\subsubsection{Civil Rights Violation}

Millions of Kenyans are living with jiggers in their bodies. There has not been a national survey to establish the actual figures of infestation but AhadiKenya gave these estimates in 2008. 2,000,000 infested country wide, 800,000 people could not vote due to jigger infestation in 2007 [7]. People afflicted with jiggers are unable to participate fully in the democratic process to influence politics in their favor, which may marginalize them even further. This is evidenced by the high number of people $(\mathrm{N}=800,000)$ who could not walk to the polling stations to exercise their democratic right, and were not provided with the voting materials to do so.

\subsection{Control Measures of Tunga penetrans}

For effective control of the flea, victims' homes need to be thoroughly fumigated using malathion [1]. Victims should also be supplied with adequate amounts of appropriate disinfectants for soaking their infected body parts.

The victim and the rest of the family have to be educated on the need to observe hygiene, encouraged to wear shoes in order to curtail the penetration of the pest into the skin [7]. To this effect, floors of residential houses, classrooms and other public utilities need to be cemented, or smeared where cementing is unaffordable. This will hamper the breeding of the jiggers.

On-host treatment is mandatory because animals act as reservoirs of the fleas hence they fuel peri- and intra-domiciliary transmission of the parasite. On-host products have been developed, such as a combination of imidacloprid and permethrin (Advantix) which prevents infestation with $T$. penetrans in animals $[13,14]$.

Off-host stages of $T$. penetrans develop best in dry soil or in dusty soil containing organic materials [12, 15, 16]. Measures aiming to interrupt the off-host development should therefore focus on physically changing the environment in which eggs, pupae, and larva develop (Off-host control). This can be done through paving streets, cementing floors, and eliminating indiscriminate waste disposal in public areas and private compounds $[17,18]$. The same can be done through focused premise treatment with deltamethrin aimed to interrupt the off-host cycle of $T$. penetrans.

For an optimal efficacy, focal spraying has to be applied at all sites where off-host development occurs especially preferred whereabouts of dogs and cats and shady places under trees or inside houses (for sandy floors) [19]. Spraying of breeding sites is better done before the parasite population has expanded, i.e., at the beginning of the dry season [12].

Prevention of the infestation, rather than the surgical extraction of already embedded sand fleas, may interrupt transmission more effectively. Zanzarin, a plant-based repellent, has been shown to effectively prevent the infestation with $T$. penetrans in areas with high attack rates. This compound would be an ideal candidate for prophylaxis [13].

Adequate tetanus vaccination is required and antibiotics are also given to prevent secondary infections. Treatment of tungiasis consists of local excision or sterile curettage. Systemic treatment with 
niridazole $30 \mathrm{mg} / \mathrm{kg}$ as a single dose is effective in case of multiple sites of infestation. Topical treatment with ivermectin, thiabendazole, metrifonate and niridazole is a successful treatment of the lesions [1].

Some efforts have been made to intervene in this distressing ordeal, spearheaded by a nongovernmental organization called Ahadi Kenya Trust. The organization, in collaboration with the government and well wishers has engaged in various intervention measures, including rescue and referral of jigger infested persons to health centers through community mobilization, identification of infested people and referring them to health centers for treatment.

\section{Conclusions and Recommendations}

Escalated poverty levels, poor hygiene, poor infrastructure in schools, poor cultural beliefs, and prolonged dry spells in many parts of Kenya, heavily influence the persistence of the jigger infestation.

Heavy jigger infestation culminates into the vicious cycle of poverty, low educational standards low self-esteem in victims, civil rights violation and other infections like HIV/AIDS secondary infections like gangrene, sepsis, and tetanus.

Improving hygiene and sanitation in dwellings, raising economic standards of the poor, fumigation, disinfecting the victims' bodies, and use of repellants (Zanzarine) are effective control measures.

Tungiasis is a problem which has for years been ignored. The reality however is that the menace exists in our midst, affecting the core sectors of our livelihood as Kenyans-agriculture, education, social wellbeing and the economy. All stake holders should therefore step up efforts towards eliminating this menace. Communities need to be sensitized on how to curb this ordeal, and avoid stigmatizing the victims, for it is not a curse as believed by some of them.

One needs to be physically, emotionally and socially sound to deliver the much needed services of national development appropriately. The jigger infestation negatively impacts on these aspects of human health hence hampering the wholesome participation in nation building by both the affected and the infected.

For effective control of the jigger menace, the authors recommend that focal premise spraying as well as man and animal treatment should be conducted simultaneously to prevent re-infection.

The government should allocate more funds for easy facilitation of the anti-jigger campaigns in worst hit areas. The authors also wish to suggest further research on the use of Sodium bicarbonate (Magadi soda) in jigger treatment and control.

\section{References}

[1] J. Heemskerk, I. van Empel, J.J. Jakimowicz, Tunga penetrans-A case report and review of the literature, Actachirbelg. 105 (2005) 548-550.

[2] F. Hermann, E. Margit, E. van Marck, M. Heinz, R. Ronaldo, J. Heukelbach, Investigations on the biology, epidemiology, pathology and control of Tungapenetrans in Brazil: IV. Clinical and histopathology, Parasitol Res. 94 (2004) 275-282.

[3] D. Pilger, S. Schwalfenberg, J. Heukelbach, L. Witt, H. Mehlhorn, et al., Investigations on the biology, epidemiology pathology and control of Tungapenetrans in Brazil VII: The importance of animal reservoirs for human infestation, Parasitol Res. 102 (2008) 875-880.

[4] J. Heukelbach, A.M. Costa, T. Wilcke, N. Mencke, H. Feldmeier, The animal reservoir of Tunga penetrans in severely affected communities of north-east Brazil, Med. Vet. Entomol. 18 (2004) 329-335.

[5] H. Feldmeier, M. Eisele, R.C. Sabóia-Moura, J. Heukelbach, Severe tungiasis in underprivileged communities: Case series from Brazil, Emerg Infect Diseases [Online], Vol. 9, 2003, http://wwwnc.cdc.gov/eid/article/9/8/03-0041.htm.

[6] S.W. Mark, Medical Entomology for Students, 3rd ed., Oxford University Press, Liverpool, UK, 2004.

[7] Ahadi Kenya Trust Web Site, http://www.AhadiKenya Trust.org.

[8] N. Erik, Communicable Diseases: A Manual for Health Workers in Sub Saharan Africa, 3rd ed., African Medical Research Foundation (AMREF), Nairobi, Kenya, 1999, pp. 26-27.

[9] D. Pilger, S. Schwalfenberg, J. Heukelbach, L. Witt, N. Mencke, et al., Controlling tungiasis in an impoverished community: An intervention study, Plos.Negl. Trop. Dis. 2 (2008) 324. 
[10] K. Alfred, Factors Associated with Jigger Infestation in Kituro, Baringo Central District, A rapid appraisal report, 2009.

[11] K. Lilian, Knowledge, Attitude and Practice Study on Tunga penetrans Problem in Nyanchwa and Nyaura Regions of Kisii Municipality, A rapid appraisal report, 2009.

[12] J. Heukelbach, T. Wilcke, G. Harms, H. Feldmeier, Seasonal variation of tungiasis in an endemic community, Am. J. Trop. Med. Hyg. 72 (2005) 145-149.

[13] H. Feldmeier, J.D. Kehr, J. Heukelbach, A plant-based repellent protects against Tunga penetrans infestation and sand flea disease, Acta. Trop. 99 (2006) 126-136.

[14] S. Klimpel, H. Mehlhorn, J. Heukelbach, H. Feldmeier, Mencke: Field trial of the efficacy of a combination of imidacloprid and permethrin against Tungapenetrans (sand flea, jigger flea) in dogs in Brazil, Parasitol Res. 97 (2005) 113-119.
[15] J. Heukelbach, F.A. Oliveira, G. Hesse, H. Feldemeier, Tungiasis: A neglected health problem of poor communities, Trop Med. Int. Health 6 (2001) 267-272.

[16] G.B. White, Ectoparasites: Leeches and leech infestaton, myiasis, jigger fleas, scabies, louse infestation, in: G. Cook, A. Zumla (Eds.), Manson's Tropical Diseases, 21st ed., London, 2002, pp. 1599-1611.

[17] J. Heukelbach, F.A. Oliveira, H. Feldmeier, Ectoparasitoses and public health in Brazil: Challenges for control, Cad Saude Publica 19 (2003) 1535-1540.

[18] U.S. Ugbomoiko, L. Ariza, I.E. Ofoezie, J. Heukelbach, Risk factors for tungiasis in Nigeria: Indentification of targets for effective intervention, Plos. Negl. Trop. Dis. 8 (2007) 87.

[19] L. Witt, J. Heukelbach, S. Schwalferberg, R.A. Ribeiro, G. Harms, H. Feldmeier, Infestation of Wistar rats with Tungapenetrans in different microenvironments, Am. J. Trop. Med. Hyg. 76 (2007) 666-668. 